\title{
(2) OPEN ACCESS \\ Reporting incidents involving the use of advanced medical technologies by nurses in home care: a cross-sectional survey and an analysis of registration data
}

\author{
Ingrid ten Haken (D) ,' Somaya Ben Allouch, ${ }^{2}$ Wim H van Harten ${ }^{3,4}$
}

- Additional material is published online only. To view please visit the journal online (http://dx.doi.org/10.1136/ bmjqs-2019-010510).

${ }^{1}$ Research Group Technology, Health \& Care, Saxion University of Applied Sciences, Enschede, The Netherlands

${ }^{2}$ Research Group Digital Life, Amsterdam University of Applied Sciences, Amsterdam, The Netherlands

${ }^{3}$ Health Technology \& Services Research, Faculty of Behavioural, Management and Social Sciences, University of Twente, Enschede, The Netherlands ${ }^{4}$ CEO, Rijnstate General Hospital, Arnhem, The Netherlands

\section{Correspondence to} Ingrid ten Haken, Research Group Technology, Health \& Care, Saxion University of Applied Sciences - AMM, P.O. Box 70.000 , Enschede 7500 KB, The Netherlands;

i.tenhaken@saxion.nl

Received 17 October 2019

Revised 29 April 2020

Accepted 20 May 2020

Published Online First

16 June 2020

\section{Check for updates}

(c) Author(s) (or their employer(s)) 2021. Re-use permitted under CC BY-NC. No commercial re-use. See rights and permissions. Published by BMJ.

To cite: ten Haken I, Ben Allouch S, van Harten WH. BMJ Qual Saf

2021:30:380-387.

\begin{abstract}
Background Advanced medical technologies (AMTs), such as respiratory support or suction devices, are increasingly used in home settings and incidents may well result in patient harm. Information about risks and incidents can contribute to improved patient safety, provided that those are reported and analysed systematically.

Objectives To identify the frequency of incidents when using AMTs in home settings, the effects on patient outcomes and the actions taken by nurses following identification of incidents.

Methods A cross-sectional study of 209 home care nurses in the Netherlands working with infusion therapy, parenteral nutrition or morphine pumps, combining data from a questionnaire and registration forms covering more than 13000 patient contacts. Descriptive statistics were used.

Results We identified 140 incidents (57 adverse events; 83 near misses). The frequencies in relation to the number of patient contacts were $2.7 \%$ for infusion therapy, $1.3 \%$ for parenteral nutrition and $2.6 \%$ for morphine pumps. The main causes were identified as related to the product (43.6\%), the organisation of care $(27.9 \%)$, the nurse as a user $(15.7 \%)$ and the environment (12.9\%). $40 \%$ of all adverse events resulted in mild to severe harm to the patient. Incidents had been discussed in the team $(70.7 \%)$, with the patient/informal caregiver(s) $(50 \%)$, or other actions had been taken (40.5\%). $15.5 \%$ of incidents had been formally reported according to the organisation's protocol.

Conclusions Most incidents are attributed to product failures. Although such events predominantly cause no harm, a significant proportion of patients do suffer some degree of harm. There is considerable underreporting of incidents with AMTs in home care. This study has identified a discrepancy in quality circles: learning takes place at the team level rather than at the organisational level.
\end{abstract}

\section{INTRODUCTION}

Advanced medical technologies (AMTs), such as respiratory support and suction devices, are frequently used in home settings and incidents associated with their use may result in serious patient harm. ${ }^{12}$ Degrees of harm are defined by the WHO according to the International Classification for Patient Safety ${ }^{3}$ from 'none', 'mild', 'moderate', 'severe' to 'death'. Information about risks and incidents in the home can contribute to improved patient safety and quality of care. However, one prerequisite is that incidents are reported and analysed systematically. ${ }^{4-6}$

Risk factors identified in several studies generally relate to technological, environmental or human factors, ${ }^{7-9}$ sometimes extended with organisational factors. ${ }^{10-12}$ However, these factors cannot always be strictly separated. The performance of a professional using a device can also be seen as a joint system, and there is a mutual dependency between shaping the work environment and shaping work. ${ }^{13} 14$ In home care, there is a less controlled setting, which means that work and risk factors with the use of AMTs at home are different from those prevailing in hospitals. Another risk factor is that there are various user groups involved in the home setting: in addition to professional nurses, there are also patients and informal caregivers. ${ }^{9}{ }^{15-17}$ A review of on-call logs found that $44 \%$ of incidents involving home mechanical ventilation reported by patients were related to the device, $18 \%$ were attributed to the user and 5\% to equipment availability. ${ }^{18}$ A Canadian adverse event study ${ }^{19}$ found that $22 \%$ of the events in home care directly or indirectly involved medication, followed by fall injury (17\%) and wound infection (14\%). 
Although incidents involving medical devices occur regularly in healthcare, the literature suggests that there is a severe under-reporting by nurses. ${ }^{20}{ }^{21} \mathrm{In}$ hospitals, there are several factors that hinder professionals from reporting incidents, especially regarding the use of medical devices. Insufficient knowledge to recognise an event as an incident, pressure of time, liability concerns or the fear of punishment can be obstacles to reporting. ${ }^{52-24}$ A culture of safety within organisations, in which employees feel comfortable in reporting, and the availability of a suitable reporting system is likely to encourage users to report incidents involving medical technologies. ${ }^{20} 25$ In the home setting, there is also evidence that problems and incidents involving medical devices are underreported, ${ }^{26}$ although only limited information is available about the occurrence and reporting of incidents involving the use of AMTs by nurses at home.

Professional nurses are an important group of users of AMTs in the home. However, there remains a lack of research exploring the perspectives of nurses in using AMTs at home in terms of risk management and patient safety. ${ }^{27}$ The following three research questions will be addressed in this study: (1) what are the most frequent incidents in using AMTs by nurses in home settings and what characterises such events?; (2) what are the typical effects of incidents on the patient outcomes? and (3) which actions are typically taken by nurses, and to what extent, following incidents regarding the use of AMTs in home settings? Secondary goals are to identify whether there are correlations between the variables 'working as a specialised nurse or not' and 'the highest level of education completed in nursing' on the one hand and 'the number of reported incidents' on the other.

\section{METHODS}

\section{Study design, setting and participants}

A cross-sectional questionnaire survey combined with an analysis of registration data was conducted from July 2018 to February 2019 inclusive in the Netherlands. A representative sample of 340 nurses working in home care across the country was recruited. Respondents were selected from teams whose nurses work as Category A-a specialised nurse who performs specific care tasks for patients at home using AMTs or as Category $\mathrm{B}$ - a nurse who usually performs various care tasks for patients at home, including care with AMTs if necessary. Nurses were eligible to participate if they were working with infusion therapy, parenteral nutrition or a morphine pump, regardless of how frequently. These three technologies were selected as the focus of this study because it is known that they are often used, ${ }^{27} 28$ which is confirmed by professionals in home care practice.

\section{Instruments}

Two measurement instruments were used to collect data: a questionnaire (see online supplementary appendix 1) and an incident registration form (see online supplementary appendix 2 ). In this study, the term 'incidents' will be used to mean adverse events (incidents reaching the patient, whether or not causing harm to the patient) and near misses (incidents not reaching the patient, causing no harm to the patient). The questionnaire investigated general respondent characteristics, such as age, sex, highest level of education completed in nursing and full-time equivalent (FTE) status. It comprised questions about experiences with the three technologies and also about the reporting of incidents within their organisation. Most questions were multiple choice.

The incident registration form contained questions about the times of the shift that day, the number of patients seen during the shift, the use of the technologies and for how many patients. If an incident occurred, the respondents could attribute it to one of four categories: (1) product; (2) environment; (3) organisation of care or (4) human factors resulting from the nurse as user of the technology. The development of the registration form was partly based on the registration form used in a study into equipment-related incidents in the operating room, ${ }^{12}$ in which a PRISMA analysis was used to analyse the causes of incidents. Subcategories of possible causal attributions were based on the literature. ${ }^{29}{ }^{30}$ The effect of the incident on the patient could be indicated on the WHO five-point scale. The final section concerned the action(s) that the nurse took or did not take as a result of the event. Both the questionnaire and the incident registration form were pretested in a pilot by a team of home care nurses and adjusted based on their experiences and feedback. The adjustments were mainly to wordings.

\section{Data collection}

Respondents were recruited by email and telephone. Interested nurses were sent an envelope containing information about the study, instructions about both instruments and blank registration forms. The envelope also contained a personal respondent number, which the respondents had to fill in on both the registration forms and the questionnaire. The envelopes with the numbers were randomly distributed to the participating nurses, to ensure anonymity.

Respondents were asked to fill in one registration form per shift for 10 consecutive shifts. Once all forms had been completed, the respondents could send them back in a prepaid return envelope. About a week after sending out the postal envelopes, the respondents received an email with a link to the online survey using Qualtrics software. After about 4 weeks, the respondents received a reminder message for both instruments.

According to the policy activities that constitute research at the University of Twente, this work met the criteria for operational improvement activities exempt from ethics review and data protection rules 
were followed accordingly. The study was deemed an improvement activity in professional practice and not research on human subjects, and in line with the ethic regulations we obtained informed consent. Nurses were informed in advance via email about what participation would entail. They could then decide whether or not to participate. Completing the registration forms and the questionnaire was strictly anonymous to ensure nurses' privacy. Data cannot be traced back to individual respondents or organisations.

\section{Data analysis}

The data files of the questionnaire results and the registration forms were combined, so that the outcomes of both instruments could be related to each other on the basis of the respondents' individual numbers. If a respondent indicated more than one main cause for an incident on the registration form, then two authors reached consensus about the underlying cause. Not all respondents who experienced an incident answered all the questions, so the number of missing answers is indicated.

Descriptive statistics are provided for respondent characteristics, the use of the three technologies, the description of incidents and the follow-up. The $\chi^{2}$ test was used to identify any differences between groups of nurses. All statistical analyses were conducted using SPSS statistical software, V.24.

\section{RESULTS}

\section{Sample characteristics}

The study response after the reminder message was as follows: 209 respondents $(61.5 \%)$ completed the online questionnaire and 202 (59.4\%) completed the registration forms, with 181 respondents (53.2\%) completing both instruments. Demographic data and characteristics for the study sample are presented in table 1. Almost all respondents had followed extra or specialised education in nursing, such as wound care, intensive or coronary care, palliative care, oncology, dialysis, management in care, medical skills in nursing or home care technology.

The data collection yielded a total of 2131 usable registration forms covering morning, afternoon, evening and night shifts. Nurses visited a mean of 6.3 patients per shift, which means that this study includes more than 13000 patient contacts. During 72.1\% of their shifts, the nurses had used one or more of the technologies involving infusion therapy, parenteral nutrition or morphine pumps. For further analysis, registration forms were only included if nurses had at least one patient contact during the shift. Some respondents failed to record the number of patients. For those cases, the number of patient contacts was extrapolated, based on the known average.

Regarding infusion therapy, $81.3 \%$ of the respondents (168 of $n=208$; one missing) had more than 2 years' experience in total (in inpatient and/or outpatient care)
Table 1 Sample demographics and characteristics

\begin{tabular}{|c|c|}
\hline$N$ & 209 \\
\hline \multicolumn{2}{|l|}{ Age } \\
\hline Mean (SD) & $46.1(11.4)$ \\
\hline Missing, n (\%) & $2(1.0)$ \\
\hline \multicolumn{2}{|l|}{ Gender } \\
\hline Female, n (\%) & $188(90.8)$ \\
\hline Male, n (\%) & $19(9.2)$ \\
\hline Missing, n (\%) & $2(1.0)$ \\
\hline \multicolumn{2}{|l|}{ Employment in FTE } \\
\hline Mean (SD) & $0.7(0.2)$ \\
\hline Missing, n (\%) & $1(0.5)$ \\
\hline \multicolumn{2}{|l|}{ Highest level of education completed in nursing } \\
\hline $\begin{array}{l}\text { Higher professional education with a bachelor degree, } \\
\mathrm{n}(\%)\end{array}$ & $90(43.9)$ \\
\hline Secondary vocational education, $\mathrm{n}(\%)$ & $41(20.0)$ \\
\hline In-service education, n (\%) & $61(29.8)$ \\
\hline Other education, $n(\%)$ & $13(6.3)$ \\
\hline Missing, n (\%) & $4(1.9)$ \\
\hline \multicolumn{2}{|l|}{ Specialty } \\
\hline $\begin{array}{l}\text { Category A: a specialised nurse who performs specific } \\
\text { care tasks for patients at home using AMTs, } n(\%)\end{array}$ & $127(62.0)$ \\
\hline $\begin{array}{l}\text { Category B: a nurse who usually performs various care } \\
\text { tasks for patients at home, including the care with AMTs } \\
\text { if necessary, } n(\%)\end{array}$ & $78(38.0)$ \\
\hline Missing, $n(\%)$ & $4(1.9)$ \\
\hline
\end{tabular}

FTE, full-time equivalent.

but $6.3 \%$ had never used these technologies in practice. Of the nurses who work with infusion therapy in home care $(\mathrm{n}=187), 94.2 \%$ considered themselves as competent to use infusion therapy safely in the home setting, of which $62.6 \%$ 'very competent', but $5.9 \%$ as insufficiently competent. On average, $62.0 \%$ of the respondents ( 129 of $n=208$; one missing) use infusion therapy in home care during (almost) every shift, but 9.1\% had never used these technologies in home care. In this study, the nurses used infusion therapy at some point during $60.5 \%$ of their shifts and applied it to a total of 3022 patients, with an average of 2.4 patients per shift.

$77.8 \%$ of the respondents (161 of $n=207$, two missing) had more than 2 years' experience with parenteral nutrition, but $10.6 \%$ of the respondents had never used these technologies. Of the nurses who use these technologies in home care $(n=175), 48.6 \%$ considered their competence at using these technologies in a safe way in the home as very high, $46.9 \%$ as sufficiently high but a minority of $4.6 \%$ as insufficient. About half of the respondents (50.5\%) use these technologies during (almost) every shift (106 of $n=208$; one missing), but $14.9 \%$ had never used them in home care. In this study, these technologies were used at some point during $34.4 \%$ of the shifts, involving 1034 patients and, on average, 1.4 patients per shift.

Most nurses participating in the study (83.2\%, 173 of $n=208$; one missing) have at least 2 years' 
Table 2 Incidents (adverse events and near misses) in relation to the number of patient contacts

\begin{tabular}{llllc}
\hline & $\begin{array}{l}\text { Number of } \\
\text { patients } \\
\text { treated }\end{array}$ & $\begin{array}{l}\text { Adverse } \\
\text { events } \\
\mathrm{n}(\%)\end{array}$ & $\begin{array}{l}\text { Near } \\
\text { misses } \\
\mathrm{n}(\%)\end{array}$ & $\begin{array}{l}\text { Total of } \\
\text { incidents } \\
\mathrm{n}(\%)\end{array}$ \\
\hline $\begin{array}{l}\text { Infusion } \\
\text { therapy }\end{array}$ & 3022 & $33(1.1)$ & $47(1.6)$ & $80(2.7)$ \\
$\begin{array}{l}\text { Parenteral } \\
\text { nutrition }\end{array}$ & 1034 & $4(0.4)$ & $9(0.9)$ & $13(1.3)$ \\
$\begin{array}{l}\text { Morphine } \\
\text { pumps }\end{array}$ & 1811 & $20(1.1)$ & $27(1.5)$ & $47(2.6)$ \\
\hline \begin{tabular}{l} 
Total \\
\hline
\end{tabular} & 5867 & $57(1.0)$ & $83(1.4)$ & $140(2.4)$ \\
\hline
\end{tabular}

experience of using morphine pumps, but $0.5 \%$ had never used them. Of the nurses who use these pumps in home care $(n=202), 96.5 \%$ considered themselves as competent in the safe use of these technologies in the home (of which $59.9 \%$ 'very competent'), but $3.5 \%$ as insufficiently competent. In home care, 55.3\% (115 of $n=208$; one missing) of these nurses use morphine pumps at least once during (almost) every shift, but
$1.4 \%$ had never used morphine pumps in home care. $43.4 \%$ of the shifts registered in this study involved the use of morphine pumps, with 2.0 patients per shift on average and a total of 1811 patients in this study treated using morphine pumps.

\section{Adverse events and near misses}

Nurses who used one of the three AMTs in their shift indicated that an adverse event involving one of the technologies occurred in $3.7 \%$ of those shifts, a near miss in $5.4 \%$ of those shifts but during $90.9 \%$ of the shifts no incident occurred. Incidents involving infusion therapy occurred most frequently $(2.7 \%)$ in relation to the number of patient contacts involving that technology (see table 2), followed by morphine pumps $(2.6 \%)$ and parenteral nutrition (1.3\%).

Regarding infusion therapy, incidents $(n=80)$ were mainly attributed to the product $(46.3 \%)$, followed by the organisation of care $(25.0 \%)$, the environment $(15.0 \%)$ and the nurse as the user (13.8\%) (see table 3). Product-related incidents were mainly attributed to

Table 3 Main categories and underlying causal attributions of incidents ( $n=140)$

\begin{tabular}{|c|c|c|c|}
\hline \multirow[b]{2}{*}{ Incidents mainly attributed to } & \multicolumn{3}{|c|}{ Technology } \\
\hline & $\begin{array}{l}\text { Infusion therapy } \\
\mathrm{n}(\%)\end{array}$ & $\begin{array}{l}\text { Parenteral nutrition } \\
\mathrm{n}(\%)\end{array}$ & $\begin{array}{l}\text { Morphine pumps } \\
\mathrm{n}(\%)\end{array}$ \\
\hline Product & $37(46.3)$ & $6(46.2)$ & $18(38.3)$ \\
\hline Technical defect in the device & $14(17.5)$ & $5(38.5)$ & $11(23.4)$ \\
\hline Correct device not present or device component(s) missing & $12(15.0)$ & $0(0)$ & $2(4.3)$ \\
\hline Manual unclear, incomplete, not available or unsuitable for the home situation & $1(1.3)$ & $0(0)$ & $0(0)$ \\
\hline Device unsuitable for the home situation, because ... & $1(1.3)$ & $0(0)$ & $0(0)$ \\
\hline Incorrect medication preparation, administration or delivery & $5(6.3)$ & $1(7.7)$ & $5(10.6)$ \\
\hline Other & $4(5.0)$ & $0(0)$ & $0(0)$ \\
\hline Environment & $12(15.0)$ & $2(15.4)$ & $4(8.5)$ \\
\hline Climate in the room (eg, temperature, humidity, lighting, noise) & $0(0)$ & $0(0)$ & $1(2.1)$ \\
\hline Hygiene of the room & $2(2.5)$ & $0(0)$ & $0(0)$ \\
\hline Room too small & $0(0)$ & $0(0)$ & $0(0)$ \\
\hline Presence of children & $0(0)$ & $0(0)$ & $0(0)$ \\
\hline Presence of pets & $0(0)$ & $2(15.4)$ & $1(2.1)$ \\
\hline Power failure or interference with other electrical devices & $0(0)$ & $0(0)$ & $0(0)$ \\
\hline Incorrect use by patient and/or informal caregiver(s) & $8(10.0)$ & $0(0)$ & $1(2.1)$ \\
\hline Other & $2(2.5)$ & $0(0)$ & $1(2.1)$ \\
\hline Organisation of care & $20(25.0)$ & $4(30.8)$ & $15(31.9)$ \\
\hline Unclear tasks, responsibilities and/or authorisations & $3(3.8)$ & $2(15.4)$ & $3(6.4)$ \\
\hline Error or transfer error by a colleague or other healthcare professional & $14(17.5)$ & $2(15.4)$ & $11(23.4)$ \\
\hline Poor maintenance of the device, including cleaning & $2(2.5)$ & $0(0)$ & $0(0)$ \\
\hline Other & $1(1.3)$ & $0(0)$ & $1(2.1)$ \\
\hline Human factors: Yourself as a user & $11(13.8)$ & $1(7.7)$ & $10(21.3)$ \\
\hline Insufficient knowledge/skills regarding the use of the device & $0(0)$ & $0(0)$ & $1(2.1)$ \\
\hline Stress or fatigue & $0(0)$ & $0(0)$ & $0(0)$ \\
\hline Inattention or error & $7(8.8)$ & $1(7.7)$ & $5(10.6)$ \\
\hline Failure in situational awareness & $1(1.3)$ & $0(0)$ & $0(0)$ \\
\hline Incorrect calculation of medication & $1(1.3)$ & $0(0)$ & $4(8.5)$ \\
\hline Other & $2(2.5)$ & $0(0)$ & $0(0)$ \\
\hline Total & $80(100)$ & $13(100)$ & $47(100)$ \\
\hline
\end{tabular}


technical defects in the device $(17.5 \%)$ or that the correct device was not present or a component was missing (15.0\%). Incidents related to the organisation of care were mainly attributed to an error or handover error by a colleague or other healthcare professional (17.5\%). The most common incidents related to the environment were incorrect use by patient and/or informal caregiver(s) (10.0\%). If the incident was related to the nurse as a user, inattention or error were the main causes in $8.8 \%$ of the cases.

As the main cause of an incident involving parenteral nutrition $(n=13)$, respondents mentioned the product $(46.2 \%)$, the organisation of care $(30.8 \%)$, the environment (15.4\%) and themselves as users (7.7\%). Incidents related to the product were mostly identified as a technical defect in the device (38.5\%). In the 'organisation of care' category, the respondents cited unclear tasks, unclear responsibilities and/or unclear authorisations (15.4\%) and an error or handover error by a colleague or other healthcare professional $(15.4 \%)$ as the explanation. Incidents due to environmental factors were often related to the presence of pets $(15.4 \%)$, and incidents due to themselves as users, to inattention or error $(7.7 \%)$.

Table 3 also shows that incidents involving morphine pumps $(n=47)$ were attributed to the product $(38.3 \%)$, the organisation of care $(31.9 \%)$, the nurse as a user $(21.3 \%)$ and the environment $(8.5 \%)$. The underlying aspect related to the product was usually a technical defect in the device (23.4\%). Regarding the organisation of care, the incidents were mostly related to an error or handover error by a colleague or other healthcare professional (23.4\%). The most frequent underlying aspects for the nurse as a user are inattention or error $(10.6 \%)$ and incorrect calculation of medication (8.5\%). Under environment were cited some minor factors, such as the climate in the room, the presence of pets, the incorrect use of the device by patient and/ or informal caregiver(s) and 'other'.

Regarding infusion therapy, significantly more incidents were reported by Category A nurses than Category B nurses $(\chi 2=15.077 ; \mathrm{df}=2 ; \mathrm{p}=0.001$; $\mathrm{z}=-3.785)$. However, for parenteral nutrition, no statistically significant differences could be found between the groups of nurses $\left(\chi^{2}=2.032 ; \mathrm{df}=2\right.$; $\mathrm{p}=0.362)$, nor could any such differences be identified with regard to morphine pumps $\left(\chi^{2}=4.586 ; \mathrm{df}=2\right.$; $\mathrm{p}=0.101)$. The variables of 'highest level of education completed in nursing' and 'number of reported incidents' were not statistically significant for the three technologies investigated. More descriptive statistics in relation to Category A and B nurses can be found in the online supplementary file.

\section{Effects of incidents on patient outcomes}

The near misses that occurred involving the three AMTs did not, by definition, cause any harm to the patient. With regard to the adverse events, $89.5 \%-100 \%$ led to either no harm or mild harm (see table 4). Patients suffered from moderate harm from infusion therapy (6.3\%) and from morphine pumps (5.3). Severe harm as a result of an adverse event only ever occurred when using morphine pumps (5.3\%).

\section{Actions taken following incidents}

In cases of an incident ( $\mathrm{n}=130 ; 10$ missing), 83.8\%$95.3 \%$ of the nurses had taken one or more actions to discuss the event (see table 5). When they had taken action, they most often discussed the incidents with colleagues in their team (60.0\%-80.5\%). Regarding morphine pumps and infusion therapy, 14.6\%-18.5\% of the nurses made a formal report according to the organisation's protocol, whereas none of the respondents formally reported an incident involving parenteral nutrition. Also, a considerable proportion of nurses had taken other actions following incidents involving infusion. 'Other actions' are cited as discussion with the colleague concerned; reporting to the pharmacist, the supplier or the manufacturer of the device; a report in the patient files or fixing the problem.

In cases of an incident, $4.7 \%-16.7 \%$ of the nurses had taken no action to discuss the event. Respondents did not do this for 'other' reasons than those listed on the registration form with regard to parenteral nutrition and morphine pumps (100\%); and for infusion therapy $(60.0 \%)$. They indicated that 'other' covered a one-time or well-known problem; prompt action was taken to resolve the problem and there were no adverse outcomes for the patient.

\section{DISCUSSION}

This study identified incidents (adverse events and near misses) involving the use of infusion therapy, parenteral nutrition and morphine pumps in home care. As an average over these three AMTs, we found that most incidents were primarily related to the product (43.6\%). Next, we found the organisation of care to be the second main category $(27.9 \%)$, followed by human factors involving the nurse as a user (15.7\%) and, to a lesser extent, the environment (12.9\%). A retrospective review of on-call logs that found that $44 \%$ of incidents involving home mechanical ventilation were due to device failure and $18 \%$ to user error ${ }^{18}$ is in line with the average results of our study. In addition, our study showed that $11.4 \%$ of the incidents were related to medication, either by incorrect medication preparation, administration or delivery $(7.9 \%)$ under the main category 'Product' or an incorrect calculation of medication (3.6\%) under the main category 'Human factors: yourself as a user'. This rate is much lower than the $21.5 \%$ found in a published chart review of adverse events among home care clients. ${ }^{19}$ However, that study did not focus on medical devices whereas our study did.

We found that significantly more incidents are registered by specialised nurses (Category A) when using infusion therapy than by nurses (Category B), the latter 
Table 4 Degrees of harm of adverse events and near misses in the patient per AMT, according to the WHO ( $n=131$; nine missing)

\begin{tabular}{|c|c|c|c|c|c|c|}
\hline \multirow[b]{3}{*}{$\begin{array}{l}\text { Degree of harm according to the WHO's } \\
\text { International Classification for Patient Safety }{ }^{3}\end{array}$} & \multicolumn{4}{|c|}{ Technology } & & \\
\hline & \multicolumn{2}{|c|}{ Infusion therapy } & \multicolumn{2}{|c|}{ Parenteral nutrition } & \multicolumn{2}{|c|}{ Morphine pumps } \\
\hline & $\begin{array}{l}\text { Adverse } \\
\text { events } \mathrm{n}(\%)\end{array}$ & $\begin{array}{l}\text { Near misses } \\
\mathrm{n}(\%)\end{array}$ & $\begin{array}{l}\text { Adverse } \\
\text { events } \mathrm{n}(\%)\end{array}$ & $\begin{array}{l}\text { Near misses } \\
\mathrm{n}(\%)\end{array}$ & $\begin{array}{l}\text { Adverse } \\
\text { events } \mathrm{n}(\%)\end{array}$ & $\begin{array}{l}\text { Near misses } \\
\mathrm{n}(\%)\end{array}$ \\
\hline $\begin{array}{l}\text { None } \\
\text { Patient outcome is not symptomatic, or no } \\
\text { symptoms detected and no treatment is required. }\end{array}$ & $19(59.4)$ & $43(100)$ & $3(75.0)$ & $8(100)$ & $11(57.9)$ & $25(100)$ \\
\hline $\begin{array}{l}\text { Mild } \\
\text { Patient outcome is symptomatic, symptoms } \\
\text { are mild, loss of function or harm is minimal or } \\
\text { intermediate but short term, and no or minimal } \\
\text { intervention (eg, extra observation, investigation, } \\
\text { review or minor treatment) is required. }\end{array}$ & $11(34.4)$ & $0(0)$ & $1(25.0)$ & $0(0)$ & $6(31.6)$ & $0(0)$ \\
\hline $\begin{array}{l}\text { Moderate } \\
\text { Patient outcome is symptomatic, requiring } \\
\text { intervention (eg, additional operative procedure, } \\
\text { additional therapeutic treatment), an increased } \\
\text { length of stay, or causing permanent or long-term } \\
\text { harm or loss of function. }\end{array}$ & $2(6.3)$ & $0(0)$ & $0(0)$ & $0(0)$ & $1(5.3)$ & $0(0)$ \\
\hline $\begin{array}{l}\text { Severe } \\
\text { Patient outcome is symptomatic, requiring life- } \\
\text { saving intervention or major surgical/medical } \\
\text { intervention, shortening life expectancy or causing } \\
\text { major permanent or long term harm or loss of } \\
\text { function. }\end{array}$ & $0(0)$ & $0(0)$ & $0(0)$ & $0(0)$ & $1(5.3)$ & $0(0)$ \\
\hline $\begin{array}{l}\text { Death } \\
\text { On balance of probabilities, death was caused or } \\
\text { brought forward in the short term by the incident. }\end{array}$ & $0(0)$ & $0(0)$ & $0(0)$ & $0(0)$ & $0(0)$ & $0(0)$ \\
\hline \multirow[t]{2}{*}{ Total } & $32(100)$ & $43(100)$ & $4(100)$ & $8(100)$ & $19(100)$ & $25(100)$ \\
\hline & $(n=75)$ & & $(n=12)$ & & $(n=44)$ & \\
\hline
\end{tabular}

AMT, advanced medical technology.

Table 5 Actions taken to discuss the incident ( $n=130 ; 10$ missing)

\begin{tabular}{|c|c|c|c|}
\hline \multirow[b]{2}{*}{ Actions taken } & \multicolumn{3}{|c|}{ Technology } \\
\hline & $\begin{array}{l}\text { Infusion therapy } \\
\mathrm{n}(\%)\end{array}$ & $\begin{array}{l}\text { Parenteral nutrition } \\
\mathrm{n}(\%)\end{array}$ & $\begin{array}{l}\text { Morphine pumps } \\
\mathrm{n}(\%)\end{array}$ \\
\hline Yes & $65(86.7)$ & $10(83.8)$ & $41(95.3)$ \\
\hline No & $10(13.3)$ & $2(16.7)$ & $2(4.7)$ \\
\hline Total & $75(100)$ & $12(100)$ & $43(100)$ \\
\hline \multicolumn{4}{|l|}{ Specification Yes (multiple answers possible) } \\
\hline Discussed it with colleagues in the team & $43(66.2)$ & $6(60.0)$ & $33(80.5)$ \\
\hline Discussed it with the direct supervisor & $5(7.7)$ & $0(0)$ & $4(9.8)$ \\
\hline Discussed it with the patient and/or the informal caregiver(s) & $39(60.0)$ & $6(60.0)$ & $13(31.7)$ \\
\hline Discussed it with the attending physician & $14(21.5)$ & $0(0)$ & $9(22.0)$ \\
\hline Made a formal report according to the protocol of the organisation & $12(18.5)$ & $0(0)$ & $6(14.6)$ \\
\hline Other & $27(41.5)$ & $2(20.0)$ & $18(43.9)$ \\
\hline \multicolumn{4}{|l|}{ Specification No (multiple answers possible) } \\
\hline Lack of time & $0(0)$ & $0(0)$ & $0(0)$ \\
\hline Don't know which action(s) I should take or how & $1(10.0)$ & $0(0)$ & $0(0)$ \\
\hline Don't know whether the event is worth reporting or discussing & $4(40.0)$ & $0(0)$ & $0(0)$ \\
\hline Don't know the potential consequences with regard to liability & $1(10.0)$ & $0(0)$ & $0(0)$ \\
\hline Fear of sanctions or punishment against me & $0(0)$ & $0(0)$ & $0(0)$ \\
\hline Other & $6(60.0)$ & $2(100)$ & $2(100)$ \\
\hline
\end{tabular}


usually performing various care tasks for patients at home, including care involving AMTs if necessary. However, this does not necessarily mean that more incidents occur for Category A nurses. Specialised nurses may sooner recognise an event as an incident, although in our study, no such difference was detected in relation to parenteral nutrition or morphine pumps.

The majority of the adverse events in our study (60\%) did not cause any harm to the patient, one-third caused mild harm, and $7.3 \%$ moderate to severe harm. It is important to note that the effects of incidents on patient outcomes is a short-term estimate and the long-term effects are unknown. Furthermore, it is not yet clear what aspects cause the degree of harm and this cannot be explained from the current data. Therefore, additional research into the causes of harm and how such harms can be prevented is essential.

In about $90 \%$ of the incidents, nurses took action to discuss the event. Incidents were mainly discussed within the team $(70.7 \%)$, with the patient and/or informal caregiver(s) $(50 \%)$ or other actions were taken (40.5\%). Although a large proportion of nurses took action following incidents, only a small proportion (15.5\%) formally reported the event according to the organisation's protocol. These results mirror other studies into inpatient care that showed significant under-reporting of incidents involving AMTs. Further research is needed to explore the reasons why home care nurses often fail to formally report. Nevertheless, it can be concluded that there is a high-quality awareness among home care nurses, because various actions are taken. It can also be concluded that there is a discrepancy in quality circles: there is an implicit professional safety culture in which learning takes place more at the team level than formally at the organisational level.

One strength of this study is that it fills a gap in the research into risk management and patient safety by exploring the experiences of nurses in using AMTs in home care. The study is also based on a representative sample, a high response rate of more than $53 \%$ for both instruments and includes a large number of patient contacts. This means that the findings can be generalised to a national picture for the Netherlands and that those findings provide a reliable insight into the practice of home care regarding the use of AMTs. Categories on the registration form are based on those recommended in the literature, which contributes to the study's validity. However, those categories are based on the hospital setting and not yet on the home setting. Previous research has shown that actual figures for the number of medical technologies used in outpatient practice were not available. ${ }^{27}$ Our study provides more detail about the extent to which certain AMTs are used in home care.

This study also has some limitations. Participation was on a voluntary basis. It is possible that those who participated were nurses with a particular interest in patient safety or who are particularly critical or reflective, although the results do not suggest that. However, it appears that nurses are critical to widely varying degrees: some registered an incident after almost every shift, repeatedly identifying the same issue, but some never registered an incident. The question arises whether all nurses correctly recognise an event as an incident and, if they do, whether it is associated with an AMT. A more valid method would be to observe nurses in their use of AMTs, but that would be challenging to organise in home care. Another limitation is that a self-report registration form was used, which inevitably involves subjectivity and implies inherent bias. Respondents could provide what they considered to be socially acceptable answers in favour of themselves, their organisation or their profession.

Nevertheless, the results contribute to the development of the nursing profession and of risk management within home healthcare organisations. It is likely that the results can be generalised to a broader international perspective for other industrialised countries. This study only focused on three AMTs. In the future, more technologies will be introduced to the home setting, especially e-health and telemonitoring. The absolute number of incidents may well increase as a result, as will the variety of such events. Home care nurses will need further training to better recognise incidents. It is worth considering reinforcing safety management at the team level rather than at the organisational level. It is also advisable to involve other professionals more in the quality circle, such as pharmacists and device manufacturers. In the future, AMTs will increasingly be developed as much for the home care setting as for hospital care. More research is needed into how more control can be realised over product-related technical defects and human aspects in the event of an incident, and the most effective quality circle in home care to help minimise patient harm.

\section{CONCLUSION}

This study has identified the most frequent incidents in the use of three AMTs by nurses in home care settings in the Netherlands, the effects on patient outcomes and which actions are taken by nurses following identification of incidents. Most incidents are related to the product and most incidents involve infusion therapy, although morphine pumps come close. Most events have no consequences for the patient. However, a significant proportion of patients suffer some degree of harm. This study has also revealed that, as in institutionalised care, there is considerable under-reporting of incidents involving AMTs in home care. The results fill a gap in the research into risk management and patient safety in the use of AMTs in home care by nurses and contribute to the literature on this topic.

Acknowledgements The authors thank all those home care nurses across the Netherlands who participated in this study and generously gave of their time and shared their experiences.

Contributors ItH was involved in the conception and design of the study, acquisition, collection of data, analysis and 
interpretation of data and drafting the article. SBA and $\mathrm{WvH}$ have made substantial contributions to the conception and design of the study, the analysis and interpretation of data and revising the article critically for important intellectual content. All authors have approved the final article, this submission and its publication.

Funding The authors have not declared a specific grant for this research from any funding agency in the public, commercial or not-for-profit sectors.

Disclaimer This article describes original work, has not been published previously and is not under consideration by any other journal. All authors meet the criteria for authorship and all those entitled to authorship are listed as authors.

Competing interests None declared.

Patient consent for publication Not required.

Provenance and peer review Not commissioned; externally peer reviewed.

Data availability statement Data are available on reasonable request. The data that support the findings of this study are available from the corresponding author $\mathrm{ItH}$, on reasonable request.

Open access This is an open access article distributed in accordance with the Creative Commons Attribution Non Commercial (CC BY-NC 4.0) license, which permits others to distribute, remix, adapt, build upon this work noncommercially, and license their derivative works on different terms, provided the original work is properly cited, appropriate credit is given, any changes made indicated, and the use is noncommercial. See: http://creativecommons.org/licenses/by-nc/4. $0 /$.

\section{ORCID iD}

Ingrid ten Haken http://orcid.org/0000-0002-7480-9414

\section{REFERENCES}

1 Brown S, Morrison AE, Parmentier CM, et al. [13]_Infusion Pump Adverse Events.pdf. J Intraven Nurs 1997;20:41-9.

2 IGZ. Risico's van medische technologie onderschat. Den Haag: Staatstoezicht op de volksgezondheid, 2008.

3 WHO. Conceptual framework for the International classification for patient safety: version 1.1, 2009. Available: http//www_who_int/patientsafety/

4 Williams SK, Osborn SS. The development of the National reporting and learning system in England and Wales, 20012005. Med J Aust 2006;184:65-8.

5 Mahajan RP. Critical incident reporting and learning. $\mathrm{Br} J$ Anaesth 2010;105:69-75.

6 Leape LL. Reporting of adverse events. N Engl J Med 2002;347:1633-8.

7 Fu M, Weick-Brady M, Tanno E. Medical devices in the home: a unique challenge for the FDA. Work 2012;41:361-5.

8 Verkerke GJ, ten Cate Hoedemaker HO, Drost R. Medische Technologie at risk? Onderzoek naar risico's bij medische technologie en mogelijkheden om deze te voorkomen of te reduceren; 2011.

9 Weick-Brady M, Singh S. The food and drug administration's initiative for safe design and effective use of home medical equipment. Home Healthc Nurse 2014;32:343-8.

10 Hilbers E, de Vries C, Geertsma R. Veiligheid van medische technologie in de thuissituatie. Een analyse op basis van onderzoek van technische dossiers van fabrikanten. RIVM Rapport 360050022/2009. Bilthoven: Rijksinstituut voor Volksgezondheid en Milieu, 2009.

11 Carayon P, Schoofs Hundt A, Karsh B-T, et al. Work system design for patient safety: the SEIPS model. Qual Saf Health Care 2006;15(Suppl 1):i50-8.
12 Wubben I, van Manen JG, van den Akker BJ, et al. Equipmentrelated incidents in the operating room: an analysis of occurrence, underlying causes and consequences for the clinical process. Qual Saf Health Care 2010;19:e64.

13 Dekker S, Hollnagel E. Human factors and folk models. Cogn Technol Work 2004;6:79-86.

14 Hollnagel E. Human factors/ergonomics as a systems discipline? "The human use of human beings" revisited. Appl Ergon 2014;45:40-4.

15 Lang A, Edwards N, Hoffman C, et al. Broadening the patient safety agenda to include home care services. Healthc Q 2006;9 Spec No:124-6.

16 Weick-Brady MD, Lazerow RN, Devices M. Medical devices: promoting a safe migration into the home. Home Healthc Nurse 2006;24:298-304.

17 U.S. Food and Drug Administration. Medical device home use initiative. USA: Center for Devices and Radiological Health, 2010: 1-9. http://www.fda.gov/downloads/MedicalDevices/ ProductsandMedicalProcedures/HomeHealthandConsumer/ HomeUseDevices/UCM209056.pdf

18 Yang L, Nonoyama M, Pizzuti R, et al. Home mechanical ventilation: a retrospective review of safety incidents using the world Health organization international patient safety event classification. Can J Respir Ther 2016;52:85-91.

19 Blais R, Sears NA, Doran D, et al. Assessing adverse events among home care clients in three Canadian provinces using chart review. BMJ Qual Saf 2013;22:989-97.

20 Ewertsson M, Gustafsson M, Blomberg K, et al. Use of technical skills and medical devices among new registered nurses: a questionnaire study. Nurse Educ Today 2015;35:1169-74.

21 Vicente KJ, Kern S. Problems with medical devices may be severely under-reported. Nurs Leadersh 2005;18:82-8.

22 Evans SM, Berry JG, Smith BJ, et al. Attitudes and barriers to incident reporting: a collaborative hospital study. Qual Saf Health Care 2006;15:39-43.

23 Samore MH, Evans RS, Lassen A, et al. Surveillance of medical device-related hazards and adverse events in hospitalized patients. JAMA 2004;291:325-34.

24 WHO. Summary of the evidence on patient safety: implications for research, 2008. ISBN: 9789241596541.

25 Gandhi TK. HTM Plays 'Critical Role' in Patient Safety, NPSF Leader Says. Biomed Instrum Technol 2015;49:269-72.

26 IGZ. Patientveiligheid: de toepassing van geneesmiddelen en medische hulpmiddelen in zorginstellingen en thuis. Den Haag; 2004.

27 Ten Haken I, Ben Allouch S, van Harten WH. The use of advanced medical technologies at home: a systematic review of the literature. BMC Public Health 2018;18:1-33.

28 Hollestelle M, Hilbers E, van Tienhoven E. Geavanceerde medische technologie in de thuissituatie: inventarisatie, gebruikersaantallen en risico's. RIVM rapport 265011004/2005. Bilthoven: Rijksinstituut voor Volksgezondheid en Milieu RIVM, 2005.

29 World Health Organisation. Better knowledge for safer care: human factors in patient safety, 2009. Available: http://www. who.int/patientsafety/research/methods_measures/human factors/human_factors_review.pdf

30 Hessels J, de Vries C, Hilbers E. Risico's bij gebruik van complexe medische technologie in de thuissituatie. Stand van zaken 2013. RIVM Rapport 2014-0061. Bilthoven; 2014. 